\title{
The Learning Experience: Training Teachers Using Online Synchronous Environments
}

\author{
Stuart Woodcock \\ Macquarie University \\ Ashley Sisco \\ Western University \\ Michelle Eady \\ University of Wollongong
}

This study examined the effectiveness of an online synchronous platform used for training preservice teachers. A blended learning approach was implemented. Fifty-three students participated in the course. Qualitative interview data and quantitative survey data were collected about students' experiences using the platform, and analyzed via thematic content analysis and statistical analysis, respectively. The findings show that e-learning synchronous technology is an effective learning tool in enhancing preservice teachers' e-learning competency in subject matter and information communication technology skills. However, preservice teachers' competency to learn and implement e-learning for students is dependent on four hierarchal conditions (a) ease of use, (b) psychologically safe environment, (c) elearning self-efficacy, and, (d) competency. Implications from the findings and future research recommendations are also presented.

\section{Introduction}

E-learning is now an established and growing practice in postsecondary (trade school, college, or university) education due to advances in information communication technology (ICT), the greater use of the Internet, and postsecondary institutions' attempts to reduce costs associated with classroom instruction (Hew \& Cheung, 2013; Pillay \& Reynold, 2014; Starcic, 2010; Vargas \& Tian, 2013; Woldab, 2014). E-learning is becoming increasingly embedded into Australian postsecondary institutions in particular; Australia is a world leader in online education, after which countries like Canada model their initiatives (Pillay \& Reynold, 2014; Sisco, 2010).

Couched within the broader Australian educational reform of focus on quality teaching (O'Meara, 2011), training teachers to effectively teach with technology (e-teach) and engage a new generation of e-learners is paramount (Vargas \& Tian, 2013). The Australian Government's strategy for "bringing schools and teachers into the information age" (Jones, 2010, p. 1) includes goals to improve preservice teacher competencies in ICT. Technology is embedded throughout the new Australian National Curriculum (Australian Curriculum and Assessment Reporting Authority, 2013), enforcing the importance of ensuring new teachers are prepared and competent to take on these challenges. Woldab (2014) argues that such training should be offered to preservice teachers and should be experiential, such that they learn about e-teaching by practicing. While training teachers to e-teach is becoming more common, it is outpaced by the rapid uptake of e-learning (Pillay \& Reynold, 2014; Thompson, Miller, \& Franz, 2013; Woldab, 2014). Although limited, existing studies on the use of 
e-learning to train preservice teachers have shown that those who e-learn perform as well with those who learn face-to-face on standardized tests and report comparable satisfaction levels (Thompson et al., 2013).

While the imperative to train teachers to effectively teach with technology is clear, the type of elearning that should be used for such training-synchronous (live time) e-learning (e.g., video conferencing, live text or audio chat, etc.) or asynchronous (at one's own pace) e-learning (e.g., email, blogging, etc.)-remains uncertain. Synchronous learning can be less convenient and more intimidating for students who prefer the flexibility and anonymity that asynchronous platforms offer (Sun, Finger, \& Liu, 2014). However, some studies suggest that synchronous e-learners tend to enjoy more consistent communication, greater focus on tasks, increased participation, and more frequent completion of their work and courses than their asynchronous counterparts (Sun et al., 2014).

Ultimately, existing research on the use of synchronous e-learning to train preservice teachers to eteach is limited (Sun et al., 2014). At the same time, practitioner input into research in this field is also lacking (Kinshuk, Hui-Wen, Sampson, \& Chen, 2013). Therefore, the present study fills a gap in the research by examining the effectiveness of an online synchronous platform used for training preservice teachers as part of their undergraduate degree, based on practitioner action research. The question guiding this research is, "To what extent can a synchronous platform be effective in facilitating learning opportunities for preservice teachers?"

\section{Method}

\section{Participants}

Fifty-three preservice teachers enrolled in a primary teacher education course at a large Australian university participated in the study. Of the participants in the study, $25 \%$ were male and $75 \%$ were female with varying ICT skills. This breakdown by gender is similar to the ratio of male and female primary teachers in Australia (Australian Bureau of Statistics, 2012). Some of the participants were located near the university and others commuted a substantial distance. Participants were selected based on random sampling.

\section{Context}

This empirical study observed the implementation of an online, live-time platform, within a subject at an Australian university. Online synchronous platforms have been used in various educational contexts from early childhood education to postsecondary education worldwide. They can be user friendly and have a range of features including the ability to share various forms of content, such as documents and Web sites. Audiovisual features provide options to talk, text, and work in small groups (Porter \& Sturm, 2006).

These platforms are currently being used to implement learning opportunities in many educational contexts, such as with primary students $(\mathrm{K}-12)$ in South Australia and with adult learners across the province of Ontario in Canada. These platforms can often present like a face-to-face learning environment in a virtual context. Similar to a lecture theater, the systems allow participants to see one another, download PowerPoint presentations to use as teaching tools and provide the elements of personal interaction, which a live-time, face-to-face classroom can offer. However, the online environment also provides students and instructors with a degree of flexibility necessary to prepare learners for educational and employment opportunities. 
A blended learning approach, including both face-to-face and online lectures via the synchronous online platform, was employed. The online tutorials provided flexibility for the "at-a distance" learners and learner-earners (students employed outside of their studies), many of whom worked in schools as teacher aides as well as those who simply preferred to work from home.

\section{Instrument}

This study employed a survey instrument containing items designed to encourage preservice teachers to self-asses their learning experience with an online synchronous platform. Items were developed based on the literature reviewed. The survey was divided into a number of parts, using a variety of question formats (e.g., open-ended questions and Likert-scale questions). Open-ended questions were used as they can be an effective tool for yielding opinions and attitudes, as well as individual responses generally (see, e.g., de Vaus, 2002; Fraenkel \& Wallen, 2006). This type of questioning can be useful when investigating research questions, which are more exploratory in nature (Creswell, 2002). Likert scale questions were also utilized and responses ranged from 0 (very poor or very inconvenient) to 6 (excellent or extremely convenient) in relation to the online tutorial. While the focus of this article is on participating preservice teachers' experiences as learners, their experiences as teachers are highlighted in a more extensive project.

\section{Procedure}

A core subject that was taught over a 13-week semester in the third year of the Bachelor of Education (BEd) primary degree course consisted of 16 tutorial groups of 26-29 students. The total population enrolled in the degree course was 432 students. All 16 of the tutorial groups were numbered, and two of the tutorial groups were randomly selected to participate in the course through the online synchronous platform. All of the other tutorial groups were taught face-to-face in the classroom throughout the semester. The students who were in the online tutorial groups were given a document, which explained how to access the online synchronous platform on their home computers and provided graphics to help guide them through the step-by-step process. Students attended a single introductory session to ensure they were able to download the platform and sign into the virtual classroom successfully.

The first week of class, the instructor facilitated a 1-hr orientation session about the synchronous online platform, during which the students were shown the basic functionalities of the platform and encouraged to try all of the tools. Over the 13-week course, the tutorial groups (face-to-face and online) covered the same content and in similar ways. The platform gave students the opportunity to respond to questions through the use of interactive icons (e.g., clapping hands, laughing, yes/no), as well as a microphone and video camera. Students were also able to share applications and Web sites, import PowerPoint slides and documents, participate in surveys and breakout room sessions (where students are placed in virtual mini classrooms to work in smaller groups), text chat, write and draw on the whiteboard, and save their work in PDF format. Moreover, all sessions in the synchronous online platform were recorded, so that students could revisit them at any time.

At the end of the 13-week semester, a survey instrument was administered to the participants. It should be noted that participation in the survey was voluntary, and that the Human Research Ethics Committee of the participating university approved the survey.

The main data collected and analysis conducted were qualitative in nature. Qualitative analysis included a thematic content analysis of responses to the open-ended questions. This form of analysis allows a researcher to "sift through large volumes of data with relative ease in a systematic fashion" 
(Stemler, 2001, p. 1). Thematic content analysis involves establishing categories into which data are organized for analysis (Guba \& Lincoln, 2000). In the present study, content analysis was used to organize the transcribed data and to establish themes. The first step in this process was an informal data analysis that used a constant comparative method for coding. This term, coined by Silverman (2000), was first introduced as checking accuracy of fit (Glasser \& Strauss, 1967; Ritchie \& Lewis, 2003). For this study, the process involved reading through the transcribed data to discover pieces that fit together in a particular evolving theme. Data were then placed into tables of the recurring themes under the appropriate heading.

Quantitative data were also collected to complement the main qualitative data. Basic statistical analysis, such as calculation of mean scores, was conducted to corroborate qualitative findings through descriptive statistics. As discussed, the qualitative analysis was foregrounded to capture the nuance in the rich qualitative data collected. The closed questions allowed for some basic quantitative analysis to supplement the qualitative data collected from the open-ended questions.

\section{Results}

Participants described in their open-ended responses the learning experience as "engaging" and "interactive." Many reported that the flexibility of the online platform made the tutorial more "accessible" and "convenient." The participants' mean rating for the tutorial session on the online learning platform was very positive $(M=5.00$; see Table 1$)$.

Table 1: Likert-Scale Questionnaire Mean Score and Response Rate by Item

\begin{tabular}{|c|c|c|}
\hline Questionnaire Item & Mean & $S D$ \\
\hline $\begin{array}{l}\text { Overall, how did you rate the tutorial sessions on Centra? Please rate on a scale } \\
\text { of } 0 \text { (very poor) to } 6 \text { (excellent). }\end{array}$ & 5.00 & 1.34 \\
\hline $\begin{array}{l}\text { As a student, how did you rate your learning and understanding on Centra? } \\
\text { Please rate on a scale of } 0 \text { (very poor) to } 6 \text { (excellent). }\end{array}$ & 4.75 & 1.18 \\
\hline $\begin{array}{l}\text { How did you rate the participation opportunities during class? Please rate on a } \\
\text { scale of } 0 \text { (very poor) to } 6 \text { (excellent). }\end{array}$ & 5.13 & 1.44 \\
\hline $\begin{array}{l}\text { How convenient was it to have this tutorial online? Please rate on a scale of } 0 \\
\text { (very inconvenient) to } 6 \text { (very convenient). }\end{array}$ & 5.60 & 1.68 \\
\hline $\begin{array}{l}\text { What was the ease of use of Centra? Please rate on a scale of } 0 \text { (not easy at all) to } \\
6 \text { (extremely easy). }\end{array}$ & 5.19 & 1.49 \\
\hline $\begin{array}{l}\text { Did you have any technical issues with Centra sessions? Please rate on scale of } 0 \\
\text { (none) to } 6 \text { (very many). }\end{array}$ & 2.72 & .81 \\
\hline $\begin{array}{l}\text { Do you feel the learning was any different to face-to-face? Please rate on a scale } \\
\text { of } 0 \text { (much worse) to } 6 \text { (much better). }\end{array}$ & 4.62 & 1.09 \\
\hline $\begin{array}{l}\text { How confident are you to participate online compared to in the classroom? Please } \\
\text { rate on a scale of } 0 \text { (less confident) to } 6 \text { (more confident). }\end{array}$ & 4.45 & 1.03 \\
\hline $\begin{array}{l}\text { How more likely are you to participate on Centra than face-to-face? Please rate } \\
\text { on a scale of } 0 \text { (less likely) to } 6 \text { (more likely). }\end{array}$ & 3.07 & .97 \\
\hline $\begin{array}{l}\text { If you had a choice in the future to choose between a Centra tutorial or face-to- } \\
\text { face, which would you choose? Please rate on a scale of } 0 \text { (face-to-face) to } 6 \\
(\text { Centra }) \text {. }\end{array}$ & 3.81 & 1.02 \\
\hline
\end{tabular}


The aforementioned thematic analysis of data resulted in the emergence of several themes. The results of the questionnaire are provided below by item themes. The relationship among these themes will be examined in the discussion session.

\section{Flexibility and Convenience}

Students located at-a-distance from campus said the online tutorial allowed them to avoid a lengthy commute. Likewise, learner-earners (students employed outside of their studies), as well as those with busy or awkward timetables (such as those with long gaps between classes), said they were able to complete coursework at their convenience. For example, one participant, who had three children, attended the live-time tutorial via iPhone while watching his/her son's soccer match. Another student was able to participate online from his/her grandmother's home. Yet another student, who was working full time as a teacher's aide, was in jeopardy of losing his/her position due to the commute to the university. The use of the online platform provided him/her with opportunity to attend the online tutorial and complete the course without compromising employment.

Moreover, those who simply prefer learning from home appreciated the option. However, the convenience of the platform depended on access to a reliable Internet connection. Some participants did not have adequate in-home Internet access. One attended the sessions from a friend's house and another from campus. The participants rated the convenience of the online tutorial as excellent $(M=$ $5.60)$.

\section{E-Learning and Understanding}

The data collected suggests that the online learning platform is a very good platform for learning and understanding $(M=4.75)$. Among the factors contributing, participants mentioned its usability, propensity to increase confidence of presenters, interactivity, visual and oral presentation of the information, and capacity to provide additional information for later reference. Furthermore, students stated that using the platform increased their "sense of accountability" of their learning.

However, participants also reported that the content and delivery of the presentations influenced their learning and understanding of the platform. For example, one participant suggested that it "depends on the presenter's ability to present ... and to get the class involved," and another commented that it was difficult to "engage" on the platform. Another participant noted that "I felt I learnt [sic] more about technology, however during [the] presentations, sometimes they weren't interesting so I found myself on Facebook but still listening to [the] presentation." One participant stated that the learning was good but would have been better in a classroom setting because he/she could concentrate better in person.

\section{Teacher Participation With E-Learning}

Overall, participants said that the online learning platform was extremely useful in encouraging participation to express views, ask questions and listen to others. Participants mentioned that the "breakout rooms," "interactive whiteboards," "emoticons," and "hand icons" encouraged increased participation. One participant noted that participation depended on the content and delivery of the presentation and that the breakout room could be awkward because "you couldn't see peoples' expressions and body language." Another participant commented that it seemed inauthentic as though "you're [not] talking to real people." Another commented that "people are more willing to contribute online which makes for more interesting, meaningful discussion." Several responded that there was increased opportunity to participate online because it was more difficult to monopolize the conversion. Therefore, it provided participants with opportunities to listen to a wider audience. 
Participants also stated they felt free to ask questions to the instructor directly and privately and to the class broadly. Participants seemed to recognize that there were limitations to eliciting participation online, compared with in-person instruction. Overall, participants rated the online learning platform as extremely good in terms of providing opportunities to participate during class $(M=5.13)$.

\section{Ease of Use of E-Learning}

Ease of use depends upon several factors, including technological issues, clarity of expectations, familiarity with tools, accessibility of "netiquette" (online etiquette), and time consumption. Technical support is also important in supporting students through the new methods of learning, in order to make them comfortable and confident with the new technology. The online learning platform used was described as being very easy to use and to learn with.

As in many education courses, there are a number of mature-aged students, many of whom have varying degrees of computer literacies (the ability and knowledge to effectively use computers). The participants who fell into this category commented on their initial apprehension. However, after their orientation to the platform, felt quite "at ease" with using a tool of its complexity.

Participants reported that the instructions they were given were clear and they had ample support. They also noted that the platform's similarity to other online and social networking applications made it easy to use. Several technical issues were reported by participants, most of which were related to connectivity. One participant noted that he/she was "kicked off" (disconnected from the online classroom) repeatedly and that this was disruptive while another noted that large video files negatively affected the connectivity. Some other technical issues pertained to the microphone and video/webcam and downloading of large PDF files from the system. Overall, ease of use of the online learning platform was rated as extremely good $(M=5.19)$.

\section{Interactivity of E-Learning}

When asked whether the "learning [with the online synchronous platform] was any different to faceto-face," participants provided mixed, and in some cases, contrary, feedback. Several participants reported that it was the same. However, results were varied in relation to the degree of interaction. For example, one participant noted that it was difficult to know what others were thinking without being able to see their facial expressions and body language; however, another participant said the provision of extra information was helpful, including the use of images and visual definitions. Moreover, while a few participants stated that it was more difficult to concentrate online due to a decreased accountability for "zoning out" in an online setting, another noted that the online platform required, and, thus, demanded greater concentration. These results can reinforce that e-learning is complimentary rather than alternative to face-to-face learning.

\section{E-learning and Teacher Self-Efficacy and Competence}

Overall, the results of the survey suggest that e-learning increases teacher self-efficacy and competence. Participants said it increased their level of self-efficacy because they were in a psychologically safe environment. Specifically, participants stated that they were able to learn from home, participate anonymously, and feel more confident to ask questions for understanding, and, thus, were more comfortable sharing their ideas in a judgment-free environment $(M=4.38)$.

However, although participants generally found the online learning platform to be easy to use, some stated in the open-ended responses that where online errors did occur, user confidence was reduced. 
Most participants reported that they were more competent (able to effectively complete their tasks) online compared with their participation in the classroom.

\section{Preference for E-Learning Versus Face-to-Face Learning}

Participants rated the online learning platform and face-to-face learning equally in terms of preference. Their open ended responses showed that access to the Internet and personal preferences (in terms of online vs. face-to-face learning) were influential. Those participants who were in favor of the online platform stated that they were more likely to participate online than face-to-face because of its flexibility and capacity to encourage greater participation. Moreover, many participants stated that if they had no other classes on campus, or the topics were theory-based, they would prefer the online platform.

Participants generally noted that both e-learning and face-to-face learning are valuable and complimentary. Other participants who favored face-to-face over the online learning platform stated that they learned better and enjoyed face-to-face learning more than online learning. Overall mean scores show that participants were slightly in favor of online learning.

\section{Discussion}

\section{Blended and Flexible Learning Approaches}

The results of this study support previous studies that found teachers are generally receptive to, and even slightly in favor of, online over in-person learning and that e-learning promotes interactivity among e-learners and teachers (Sammel, Weir, \& Klopper, 2014; Thompson et al., 2013). Specifically, e-learning was regarded as more flexible and engaging, which might be considered particularly appropriate with the increase of "learner-earners" and multitasking learners. The results also show that online synchronous learning is complimentary, rather than an alternative, to face-to-face learning. Therefore, the results of this study support previous studies, which show that online learning should be presented in a blended approach complimentary with face-to-face learning (Poon, 2013; Sisco, 2010).

\section{ICT Training Tool}

The results support previous literature, which shows that e-learning is an effective delivery mode for training preservice teachers to teach with ICT (Thompson et al., 2013). Contrary to the majority of literature, which states that many teachers are unwilling to participate in the pedagogical shift to elearning (Jones, 2010; Korthagen, 2010; Starcic, 2010; Woldab, 2014), this study has shown that when given the opportunity, preservice teachers were open to teaching and learning in an online environment. The results also support literature, which shows that e-learning facilitates a sense of accountability for self-directed, independent learning (Woldab, 2014), which is necessary to fostering deep and meaningful learning and communicating their understandings (Pillay \& Reynold, 2014).

\section{Enhancing E-Learning Competence}

In addition to the aforementioned themes listed in the results section, the thematic content analysis yielded four overarching and interrelated themes. (Appendix). One of the most important findings that emerged from this study was that these themes represent a framework for understanding the conditions that must be met sequentially, in order to enhance e-learning competence-the EPEC (i.e., ease of use, psychologically safe environment, e-learning efficacy, and competence) hierarchy of conditions for e-learning competence (see Figure 1). 


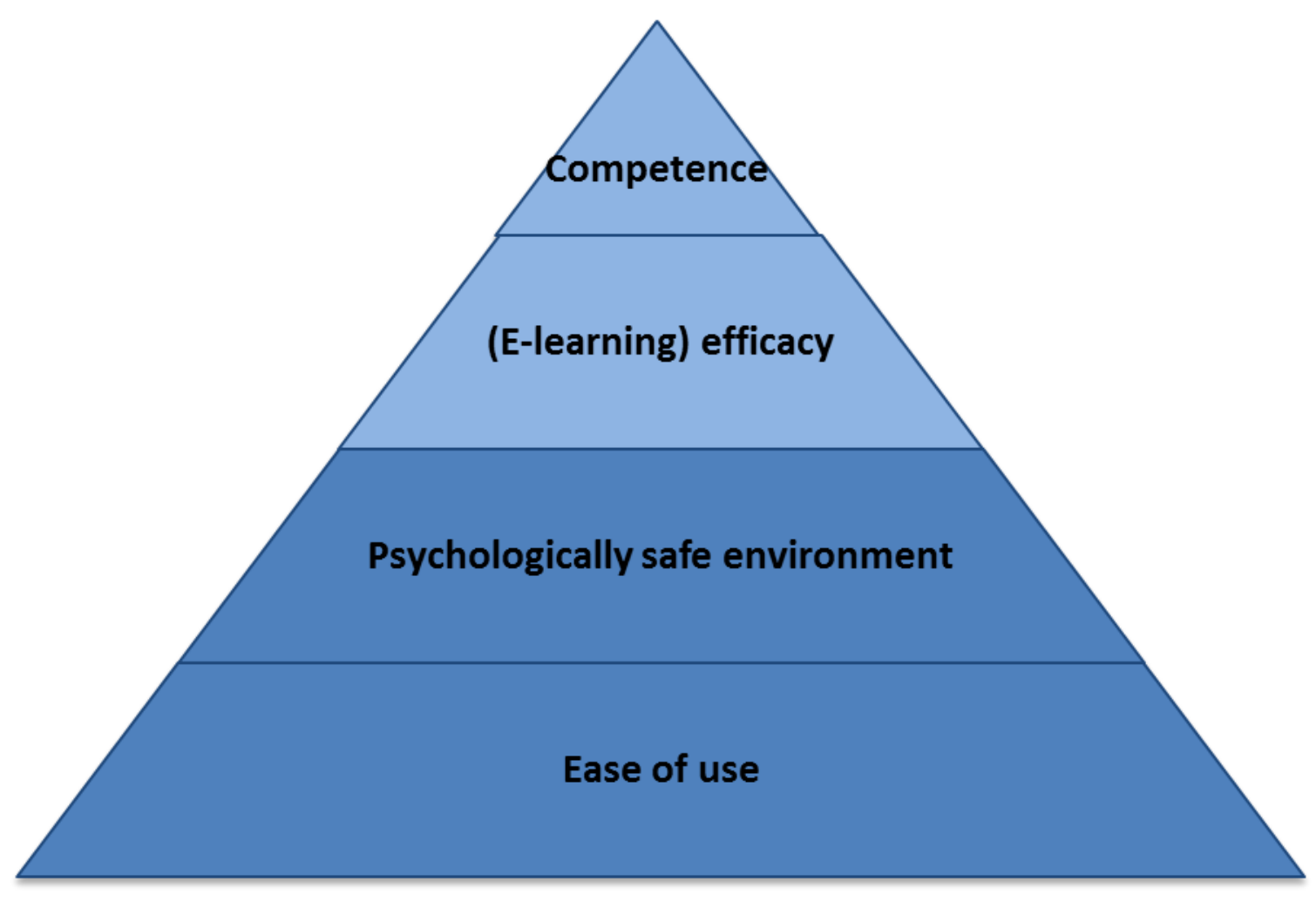

Figure 1: EPEC Hierarchy of Conditions for E-Learning Competence

As Figure 1 illustrates, e-learning competence depends on the fulfilment of (primary conditions) (a) ease of use and (b) psychologically safe environment, as well as (secondary conditions) (c) e-learning self-efficacy and (d) competence. First, an e-learning platform must be easy to use. Overly complex and difficult-to-use platforms inhibit e-learners from feeling psychologically safe in an online environment and becoming more efficacious and competent in their abilities. Second, user-friendly elearning platforms must promote a psychologically safe environment for e-learners. This means a learning environment built on the foundations of: trust and care, closeness and cohesion, mutual respect, and a democratic space of equals (Beaumont, Stirling, \& Percy, 2009; Kreijns, Kirschner, \& Jochems, 2003; Fisher, Phelps, \& Ellis, 2000). If users do not feel psychologically safe, they are unlikely to become efficacious or e-learning competent in their abilities. Third, the platform must assist e-learners in building e-learning self-efficacy. This means they must feel comfortable in the environment and confident participating. A lack of e-learning self-efficacy can inhibit e-learners from participating, and, thus, building e-learning competency.

\section{Primary Conditions}

\section{Ease of Use}

The results of this study showed that the synchronous online learning platform was easy to use and learn with. This is critical because according to Umrani-Khan and Iyer's (2009) e-learning acceptance model, effort expectancy (or perceived ease of use) is most important for student acceptance. Moreover, it challenges teacher apprehension and unwillingness to teach with technology, refuting the misconception that online synchronous platforms are difficult to learn and 
implement in their classroom. As the results show, the correlation between the platform's ease of use and the e-learner's acceptance of it are strongly linked.

\section{Psychologically Safe Environment}

The ease of use is linked with a more psychologically safe learning environment. Similar to previous studies (Beaumont et al., 2009; Fisher et al., 2000; Kreijns et al., 2003; Sun et al., 2014), the results have shown that building a learning environment on the foundations of: clear expectations, trust and care, closeness and cohesion, mutual respect, and a democratic space of equals creates a sense of psychological safety among learners that enhances their e-learning self-efficacy and experience.

When the primary conditions are met (i.e. ensuring the ease of use and the psychological safety of the online environment), the secondary conditions are then more likely to be fulfilled (i.e. e-learning self-efficacy and competence).

\section{Secondary Conditions}

\section{E-learning Self-Efficacy}

As aforementioned, results support previous studies (Lambe, 2007; Li, 2009), which showed that participants were more efficacious participating online, compared to face-to-face. Participants in this study attributed their increased e-learning self-efficacy to their ability in regards to (a) participating and asking questions to clarify their understanding anonymously and (b) joining the class from a comfortable and safe environment. This supports previous studies (e.g., de la Torre Cruz \& Arias, 2007; Mulholland \& Wallace, 2001; Roberts, Harlin, \& Ricketts, 2006; Stripling, Rickets, Roberts, \& Harlin, 2008; Woldab, 2014; Woolfolk-Hoy \& Spero, 2005), which show that self-efficacy depends on one's learning experiences (ease of use and environment). Thus, reaffirming the ease of use of the platform and the learning environment are critical for e-learning self-efficacy.

\section{Competence}

These findings support Lambe's (2007) study, which shows that e-learning competency is dependent on e-learning self-efficacy; teachers must believe they have the ability to teach effectively online before they can do so. This also supports other studies (e.g., Cakiroglu, Cakiroglu, \& Boone, 2005; Gorrell \& Dharmadasa, 1994), which show that increased teacher self-efficacy links with competency to try new teaching methods, such as e-learning, which is likely to bring about greater teacher behaviours and student achievements.

The findings also complement previous research (Dixon, Dixon, \& Axmann, 2008; Lambe, 2007; Li, 2009; Lock, 2007; Sisco, 2010; Twyford, Crump, \& Anderson, 2009), which show that e-learning improves preservice teachers' ICT competency. This is important because teachers will require ICT skills to teach with technology effectively in today's classrooms (Wilson \& Stacey, 2004) and to meet Australian university standards (Bonk, Wisher, \& Lee, 2004; Dixon et al., 2008; Lock, 2007). Moreover, such competency can provide teachers with insight into how to cater teaching material and content to student needs through technology (Li, 2009).

\section{Limitations}

While this study offers useful insights into the effectiveness of preservice teacher e-learning training, the sample size of 53 students from the same program of study at a single Australian postsecondary education institution is limited. Future research with increased numbers of participants, from varying years of study, and varying institutions is needed to generate more reliable and nuanced results. Moreover, this study considers a single synchronous platform, which might be more or less 
effective or preferred compared with other platforms. A comparative study of this synchronous online platform with others could help to determine its value.

\section{Conclusion}

The uptake of e-learning in Australia has been considerable over the past few decades, as it has moved from an alternative to a preferred mode of learning for many postsecondary students (Pillay \& Reynold, 2014; Sisco, 2010). The embedding of e-learning throughout the new Australian National Curriculum suggests that e-learning is slated to become a prominent feature in the Australian education system (Australian Curriculum and Assessment Reporting Authority, 2013; Jones, 2010). However, many Australian teachers are ill prepared to teach this new and emerging cohort of elearners (Pillay \& Reynold, 2014; Thompson et al., 2013; Woldab, 2014).

The present study demonstrated that e-learning synchronous platforms could be effective as a learning tool for preservice teachers. However, it showed that in order for preservice teachers to feel competent to learn with technology and to implement this technology, they must be involved in the elearning process. Moreover, the study showed that there are four sequential conditions for preservice teachers' e-learning competency: (a) ease of use and (b) psychologically safe environment (primary), and (c) e-learning self-efficacy and (d) competency (secondary).

It is recommended that future research consider how postsecondary institutions can best prepare preservice teachers to not only learn but also teach effectively using synchronous online platforms through the EPEC hierarchy of conditions for e-learning competence.

\section{References}

Australian Bureau of Statistics. (2012). Commentary on in-school staff, Retrieved 29 October, 2014, from http://www.abs.gov.au/ausstats/abs@.nsf/Lookup/4221.0main+features502011

Australian Curriculum and Assessment Reporting Authority. (2013, January). General capabilities in the Australian curriculum. Retrieved from www.australiancurriculum.edu.au/GeneralCapabilities/General\%20capabilities.pdf

Beaumont, R., Stirling, J., \& Percy, A. (2009). Tutors' forum: Engaging distributed communities of practice. Open Learning, 24, 141-154.

Bonk, C., Wisher, R., \& Lee, J. (2004). Moderating learner-centred e-learning: Problems and solutions, benefits and implications. In T. S. Roberts (Ed.), Online collaborative learning: Theory and practice (pp. 54-85). Hershey, PA: Idea Group Publishing.

Cakiroglu, J., Cakiroglu, E., \& Boone, W. (2005). Pre-service teacher self-efficacy beliefs regarding science teaching: A comparison of pre-service teachers in Turkey and the USA. Science Educator, 14, 31-40.

Creswell, J. W. (2002). Research design: Qualitative, quantitative and mixed methods approaches (2nd ed.). Thousand Oaks, CA: Sage Publications Inc.

de la Torre Cruz, M. J., \& Arias, P. F. C. (2007). Comparative analysis of expectancies of efficacy in inservice and prospective teachers. Teaching and Teacher Education, 23, 641-652. http://dx.doi.org/10.1016/j.tate.2007.02.005

de Vaus, D. A. (2002). Surveys in social research (5th ed.). Crows Nest, Australia: Allen \& Unwin. 
Dixon, R., Dixon, K., \& Axmann, M. (2008). Online student centred discussion: Creating a collaborative learning environment. Paper presented at the Ascilite, Melbourne, Australia. Retrieved from http://www.ascilite.org.au/conferences/melbourne08/procs/dixon.pdf

Fisher, K., Phelps, R., \& Ellis, A. (2000). Group processes online: Teaching collaboration through collaborative processes. Educational Technology \& Society, 3, 484-495.

Fraenkel, J. R., \& Wallen, N. E. (2006). How to design and evaluate research in education (6th ed.). Boston, MA: McGraw Hill.

Glasser, B. G., \& Strauss, A. L. (1967). The development of grounded theory. Chicago, IL: Alden.

Gorrell, J., \& Dharmadasa, K. (1994). Perceived self-efficacy of pre-service and in-service Sri Lankan teachers. International Education, 24, 23-36.

Guba, E., \& Lincoln, Y. (2000). Paradigmatic controversies, contradictions and emerging influences. In N. Denzin. \& Y. Lincoln (Eds.), Handbook of qualitative research (pp. 163-188). Thousand Oaks, CA: Sage Publication Inc.

Hew, K. F., \& Cheung, W. S. (2013). Designing and implementing e-learning courses: A comparative analysis of policy guidelines from nine professional organizations. International Journal of eEducation, e-Business, e-Management and e-Learning, 3, 178. http://dx.doi.org/10.7763/IJEEEE.2013.V3.218

Jones, A. (2010). ICT and future teachers: Are we preparing for e-learning? Australian Computer Society, 23, 67-69.

Kinshuk, D., Hui-Wen, H., Sampson, D., \& Chen, N. (2013). Trends in educational technology through the lens of the highly cited articles published in the journal of educational technology and society. Journal of Educational Technology \& Society, 16, 3-20.

Korthagen, F. A. J. (2010). How teacher education can make a difference. Journal of Education for Teaching, 36, 407-423.

Kreijns, K., Kirschner, P. A., \& Jochems, W. (2003). Identifying the pitfalls for social interaction in computer-supported collaborative learning environments: a review of the research. Computers in Human Behavior 19, 335-353.

Lambe, J. (2007). Student teachers, special education need and inclusion education: Reviewing the potential for problem-based, e-learning pedagogy to support practice. Journal of Education for Teaching: International Research and Pedagogy, 33, 359-377.

$\mathrm{Li}, \mathrm{B}$. (2009). The use of e-learning in pre-service teacher education. Campus-Wide Information Systems, 26, 132-136.

Lock, J. (2007). Immigration and integration: ICT in pre-service teacher education. Contemporary Issues in Technology and Teacher Education, 7, 575-589.

Mulholland, J., \& Wallace, J. (2001). Teacher induction and elementary science teaching: Enhancing efficacy. Teaching and Teacher Education, 17, 241-261.

O’Meara, J. (2011). Australian teacher education reforms: Reinforcing the problem or providing a solution? Journal of Education for Teaching, 37, 423-431.

Pillay, S., \& Reynold, J. (2014). The pains and gains of blended learning: Social constructivist perspectives. Education \& Training, 56, 254-270. http://dx.doi.org/10.1108/ET-11-2012-0118

Poon, J. (2013). Blended learning: An institutional approach for enhancing students' learning experiences. Journal of Online Learning and Teaching, 9, 271. 
Porter, P., \& Sturm, M. (2006). Crossing the Great Divides: Distance learning and flexible delivery in Adult Basic Education Research report for Ontario's Literacy and Basic Skills Program. Retrieved from http://alphaplus.ca/en/web-tools/online-publications-areportsgroup1/more/crossing-the-great-divides/cat_view/68-all-publications-and-reports/41crossing-the-great-divides.html

Ritchie, J., \& Lewis, J. (2003). Qualitative research practice: A guide for social science students and researchers. London, UK: Sage Publications.

Roberts, T., Harlin, J., \& Ricketts, J. (2006). A longitudinal examination of teaching efficacy of agricultural science student teachers. Journal of Agricultural Education, 47, 81-92.

Sammel, A., Weir, K., \& Klopper, C. (2014). The pedagogical implications of implementing new technologies to enhance student engagement and learning outcomes. Creative Education, 5, 104-113.

Sisco, A. (2010) Optimizing the effectiveness of e-learning for first nations. Ottawa, Canada: The Conference Board of Canada. Retrieved from http://www.conferenceboard.ca/elibrary/abstract.aspx?did=3614

Starcic, A. I. (2010). Educational technology for the inclusive classroom. The Turkish Online Journal of Educational Technology, 9, 26-37.

Stripling, C., Rickets, J., Roberts, T., \& Harlin, J. (2008). Pre-service agricultural education teachers' sense of teaching self-efficacy. Journal of Agricultural Education, 49, 120-130.

Stemler, S. (2001). An overview of content analysis. Practical Assessment, Research \& Evaluation, 7 , (17). Retrieved from http://pareonline.net/getvn.asp?v=7\&n=17

Sun, P. C., Finger, G., \& Liu, Z. L. (2014). Mapping the evolution of eLearning from 1977-2005 to inform understandings of eLearning historical trends. Education Sciences, 4, 155-171.

Thompson, N. L., Miller, N. C., \& Franz, D. P. (2013). Comparing online and face-to-face learning experiences for nontraditional students: A case study of three online teacher education candidates. Quarterly Review of Distance Education, 14, 233-251, 255.

Twyford, K., Crump, S., \& Anderson, A. (2009). Satellite lessons: Vocational education and training for isolated communities. Rural Society, 19, 127-135.

Umrani-Khan, F., \& Iyer, S. (2009). ELAM: a model for acceptance and use of e-Learning by teachers and students. Proceedings of the International Conference on e-Learning, Institute of Technology Bombay, Mumbai, India, pp. 475-485.

Vargas, N., \& Tian, X. (2013). E-learning: Much more than a matter of technology. International Journal of e-Education, e-Business, e-Management and e-Learning, 3, 277. http://dx.doi.org/10.7763/IJEEEE.2013.V3.240

Wilson, G., \& Stacey, E. (2004). Online interaction impacts on learning: Teaching the teachers to teach online. Australasian Journal of Educational Technology, 20, 33-48.

Woldab, Z. E. (2014). E-learning technology in pre-service teachers training: Lessons for Ethiopia. Journal of Educational and Social Research, 4, 159-166.

Woolfolk-Hoy, A., \& Spero, R. (2005). Changes in teacher efficacy during the early years of teaching: A comparison of four measures. Teaching and Teacher Education, 21, 343-356.

(Appendix follows) 


\section{Appendix}

Table A1: Outline of Relationship Between Overarching Themes (Conditions) and Themes

\section{Overarching}

Themes

\section{Relationship to Themes}

Ease of use

E-learning that is easy to use is flexible and convenient

E-learning that is easy to use is easy to learn and understand with

E-learning that is easy to use promotes teacher participation

E-learning that is easy to use has few or no technological issues, clear expectations, familiar tools, accessible "netiquette" (online etiquette), and is not overly time consuming

E-learning that is easy to use promotes interactivity

E-learning that is easy to use increases teacher self-efficacy and competence

E-learning that is easy to use contributes to preference for e-learning to face-to-face learning

Psychologically A psychologically safe e-learning environment is flexible and convenient

safe

environment

A psychologically safe e-learning environment promotes e-learning and understanding

A psychologically safe e-learning environment promotes teacher participation

A psychologically safe e-learning environment is one in which the platform is easy to use

A psychologically safe e-learning environment promotes interactivity

A psychologically safe e-learning environment increases teacher self-efficacy and competence A psychologically safe e-learning environment is contributes to preference for e-learning to face-to-face learning

E-learning efficacy

Competence
Flexible and convenient e-learning platforms promote e-learning efficacy

E-learning platforms that promote $e$-learning and understanding also promote e-learning efficacy

E-learning platforms that promote teacher participation also promote e-learning efficacy

E-learning platforms that are easy to use promote e-learning efficacy

E-learning platforms that promote interactivity also promote e-learning efficacy

E-learning platforms that promote teacher self-efficacy and competence also promote elearning efficacy

E-learning platforms that promote e-learning efficacy contribute to preference for e-learning above face-to-face learning

Flexible and convenient e-learning platforms foster e-learning competence

E-learning platforms that promote e-learning ad understanding foster e-learning competence

E-learning platforms that promote teacher participation foster e-learning competence

Easy to use e-learning platforms foster e-learning competence

E-learning platforms that promote interactivity foster e-learning competence

E-learning platforms that promote teacher self-efficacy and competence foster e-learning competence

E-learning platforms that foster e-learning competence contribute to preference for $e$ learning over face-to-face learning 
The Journal of Educational Research and Practice provides a forum for studies and dialogue that allows readers to better develop social change in the field of education and learning. Journal content may focus on educational issues of all ages and in all settings. It also presents peer-reviewed commentaries, book reviews, interviews of prominent individuals, and additional content. The objectives: We publish research and related content that examines current relevant educational issues and processes aimed at presenting readers with knowledge and showing how that knowledge can be used to impact social change in educational or learning environments. Additional content provides an opportunity for scholarly and professional dialogue regarding that content's usefulness in expanding the body of scholarly knowledge and increasing readers' effectiveness as educators. The journal also focuses on facilitating the activities of both researcher-practitioners and practitioner-researchers, providing optimal opportunities for interdisciplinary and collaborative thought through blogging and other communications.

Walden University Publishing: http://www.publishing.waldenu.edu 